\title{
Optimal Corridor Selection for a Road Space Management Strategy: Methodology and Tool
}

\author{
Sushant Sharma \\ Texas A\&M Transportation Institute, 110 N Davis Drive, Suite 106, Arlington, TX 76013, USA \\ Correspondence should be addressed to Sushant Sharma; s-sharma@tamu.edu
}

Received 5 July 2016; Accepted 10 October 2016; Published 11 January 2017

Academic Editor: Sunder Lall Dhingra

Copyright (C) 2017 Sushant Sharma. This is an open access article distributed under the Creative Commons Attribution License, which permits unrestricted use, distribution, and reproduction in any medium, provided the original work is properly cited.

\begin{abstract}
Nationwide, there is a growing realization that there are valuable benefits to using the existing roadway facilities to their full potential rather than expanding capacity in a traditional way. Currently, state DOTs are looking for cost-effective transportation solutions to mitigate the growing congestion and increasing funding gaps. Innovative road space management strategies like narrowing of multiple lanes (three or more) and shoulder width to add a lane enhance the utilization while eliminating the costs associated with constructing new lanes. Although this strategy (among many) generally leads to better mobility, identifying optimal corridors is a challenge and may affect the benefits. Further, there is a likelihood that added capacity may provide localized benefits, at the expense of system level performance measures (travel time and crashes) because of the relocation of traffic operational bottlenecks. This paper develops a novel transportation programming and investment decision method to identify optimal corridors for adding capacity in the network by leveraging lane widths. The methodology explicitly takes into consideration the system level benefits and safety. The programming compares two conflicting objectives of system travel time and safety benefits to find an optimal solution.
\end{abstract}

\section{Introduction}

According to a recent report travel delays due to traffic congestion caused drivers to waste more than 3 billion gallons of fuel and kept travelers stuck in their cars for nearly 7 billion extra hours [1] while forty-two percent of America's major urban highways remain congested [2], thus costing the economy an estimated $\$ 160$ billion or $\$ 960$ per commuter in wasted time and fuel annually. This demonstrates the direct impact of roadway congestion on economic productivity and competitiveness. Rising congestion levels increase costs to businesses while reducing the quality of travel for road users. While infusing capital in a roadway expansion and/or capacity addition are possible solutions to reducing congestion, there are two key factors to be considered before metropolitan planning organizations (MPOs) and state departments of transportation (DOTs) plan for the future. First, the studies show a growing annual funding gap to meet the financial needs of transportation projects at the federal and state levels [3-5]. Second, there is an increasing realization nationwide that there are valuable benefits to using the existing roadway facilities to their full potential in alleviating the congestion problems through innovative road space management strategies.

Cost-effective road space management strategies as alternatives to the construction of new road infrastructure ensures the enhanced utilization of existing roadways while reducing or eliminating the costs associated with building new ones. A typical capacity expansion process (adding lanes) is expensive as it involves acquiring additional right-of-way, widening the existing roadbed, and regrading roadside areas. Hence, limited availability of funding for roadway expansion and capacity addition, in conjunction with the growing congestion on the roadways, necessitates the consideration of innovative road space management strategies in the near future.

One such solution is reduced lane and shoulder widths in three or more lane roads to create a new lane and added capacity. The reduced lane widths can range from 9 to 12 feet (ft) [6]. The term "reduced lane width" in this paper implies a change in lane width, shoulder width, the number of lanes, and traffic capacity. In the past, several highway agencies have implemented projects in which an additional travel lane on an 
urban freeway is added by restriping the traveled way with narrower lanes, converting all or part of the shoulder to a travel lane, or using a combination of both [7]. The newly reconfigured lanes on a freeway can be used either as generalpurpose lanes or as High Occupancy Vehicle (HOV) lanes. The usage of the lanes subsequently influences safety differently depending on the traffic and geometric characteristics. Another practical example of lane width reduction that is not being addressed in this paper is reducing lane widths in urban arterials to provide space for other roadway features (e.g., parking) and roadside features (e.g., bicycle lanes) [8]. Further, reallocating lane and shoulder width for a fixed total paved width can be a cost-effective treatment for reducing crashes on rural, two-lane, undivided roadways [9].

Although this approach appears to be relatively simple it has two conflicting and competing objectives that need careful analysis before identifying a corridor for lane width reduction. The first objective is to increase the mobility of the road network by adding capacity, whereas at the same time the narrow lane width location should not contribute to an increase in crash rates (second objective).

Before performing the operational level analysis, an obvious research question was to analyze impacts of such measures at the system level, since the planning decisions like additional lanes may affect the travel patterns over the wider part of the network. As the pattern of trips on the network changes, the collective mobility and safety effects on the network will change. For example, it is not necessary that an increase in capacity of a particular corridor by introducing a new lane will overall improve the mobility of the network or the system level benefits. There is a well-documented case of Braess Paradox in literature [10] that shows at times an increase in capacity (supply); for example, addition of a lane or a ramp may lead to a decrease in overall system travel time or other objectives; that is, "in unfavorable situations an extension of the road network may lead to increased travel times." [10].

Further, narrowing of lanes may lead to an increase in crash rates and bottlenecks upstream or downstream. Hence, before identifying the site for lane width reduction and performing operational level studies it is critical to understand the system level implications from a planning perspective.

\section{Background Literature}

2.1. Lane and Shoulder Width Standards. The accepted standard guide for geometric design in the US, AASHTO's "Green Book" [11], recommends lane widths of $12 \mathrm{ft}(3.6 \mathrm{~m})$, for urban freeway corridors with two lanes in each direction. For corridors with three or more lanes in each direction $10 \mathrm{ft}$ $(3.0 \mathrm{~m})$ is recommended but $12 \mathrm{ft}$ is preferred. Throughout the US, freeway design standards generally comply with the Green Book in terms of lane width, but the shoulder width usage/recommendation varies from state to state. For instance, in California, the paved shoulder width is defined as the minimum continuous usable width and wider values are encouraged. This width varies from 5 up to $10 \mathrm{ft}$ depending on location and roadway cross-section. In Texas, although the state Roadway Design Manual guidelines are consistent with the Green Book values, the recommendation for shoulder widths varies. Often a shoulder width may be narrowed so that additional travel lanes can be constructed within a fixed width roadway section. The Highway Capacity Manual (HCM) also indicates that median-side lateral clearances that are greater than or equal to $2 \mathrm{ft}$ have little influence on freeway operations [12].

Similarly, for urban arterials, the recommended lane width of the divided arterials is $12 \mathrm{ft}$; however, there are circumstances when lanes less than $12 \mathrm{ft}$ should be used [11]. For example in urban areas where the use of pedestrian crossing, right-of-way, or existing development becomes an issue, lanes less than $12 \mathrm{ft}$ should be used. Also, $10 \mathrm{ft}$ lanes are acceptable in low-speed facilities and $9 \mathrm{ft}$ lanes in lowvolume residential areas [11]. In addition, there is a provision of multilane urban facilities in urban areas, where narrower inside lanes may be utilized for other road side features (e.g., bicycle lanes). In this type of situation 10-11 ft lanes are common on inside lanes with 12-13 ft utilized in outside lanes.

2.2. Traffic Operations Studies on Modifying Lane and Shoulder Width. An in-depth literature review shows the earliest studies on leveraging lane and shoulder width date back to the 1970s in California and Texas [13-15]. The first available resource from the archive is the study in Texas that examined operational and safety effects of reducing lane and shoulder width to add a lane [15]. This study examined conversion of a four-lane freeway (12 ft lanes) in Houston, Texas, into five lanes with widths of 10.5 feet by restriping and encroaching into the right shoulder. The study identified major operational benefits (28:1 as a benefit cost ratio) and concluded that reconfigured sections of freeway did not produce a significant change in the number of severe accidents during the study period after modifications.

Between 1980s-1990s most of the research documented lane width reductions specifically for work zone applications. Dudek and Richards, 1982, found lane width reduction in work zones at major freeways in San Antonio and Houston does not have a significant effect on traffic speed. Further, the number of fatality and injury rates lowered compared to historic records [16]. In contrast another study by Richards et al., 1985, evaluated speed reduction effects of reducing lane widths to 11.5 and to $12.5 \mathrm{ft}$ (i.e., $0-16 \%$ ) and found a 5$10 \mathrm{mph}$ speed reduction in urban freeways and a 10-20 mph reduction in urban arterials [17]. Rouphail et al., 1988, also found similar results in the Chicago area expressway system [18].

Benekohal et al., 1992, summarized the literature on the effectiveness of narrow lane widths to reduce speeds in work zones and concluded based on the previous studies that lane width reduction does not have consistent beneficial effects on speed. The study also found that the effectiveness of lane width reduction treatments seems to depend upon the method of reducing the lane width and length of narrow section [19]. Choueiri Elias et al., 1994, established an opposite relationship between accidents and road width; that is, accidents decrease with increasing road width up to about $25 \mathrm{ft}$ or $7.5 \mathrm{~m}$ [20]. Further, Gattis, 1999, established an inconsistent relationship between speed and lane width [21]. 
Bauer et al., 2004, studied the safety implications of reducing lane and shoulder width to increase urban freeway capacity in California. The research concluded that widening the number of lanes from four to five did have an impact on the number of crashes equivalent to an increase of approximately 11 percent in fatal and nonfatal crashes [22]. However, it was noted that the observed increase in accident frequency cannot be completely attributed to the use of a narrower lane or the conversion of a shoulder to a travel lane. The use of the added lanes as HOV lanes, which may introduce a difference in speed between adjacent lanes, may be another explanation for the increase in accidents [22]. Similar results were seen in another study where new HOV lanes were implemented by reducing lane width and converting the inside shoulder into HOV lanes [23]. The increase in crashes occurred primarily in the HOV lane and the adjacent lane.

In a driver simulator study with 20 volunteer drivers to evaluate the influence of shoulder width and guardrail placement on traffic operations observed for narrow roads with narrow shoulders, the drivers tended to position their vehicles toward the left edge of the active travel lane [24]. As the shoulder width became wider, the drivers shifted the vehicle position to the center of the lane. Finally, at locations where a guardrail was not present, the drivers positioned the vehicle toward the right edge of the travel lane for all observed shoulder widths.

In literature, the number of studies that address the issue of narrowing the lanes and shoulder width of a freeway are limited, compared to studies with nonfreeway road types. Further, the research related to the speed, safety, and operational effects of reduced lane widths provides inconsistent results, indicating that the relationships are complex and difficult to evaluate without considering other elements of the intersection or roadway environment [6]. For example, an increase in crash frequency due to reduced lane width frequency may be the result of accident migration caused by relocation of traffic operational bottlenecks.

\subsection{Crash Modification Factor for Reduced Lane and Shoulder} Width. Crash modification factor (CMF) is a multiplicative factor used to compute or predict the expected number of crashes after implementing a given countermeasure at a specific site. In Texas, subsequent research studies [25, 26] developed the CMFs, for rural and urban freeways for multiple types of corridors, lane widths, and shoulders using the base condition lane width as $12 \mathrm{ft}$ (i.e., CMF equal to one). Another independent study [27] verified these results and both studies concluded that wider lanes, shoulders, and paved surface on rural two-lane highways lead to reduction in the number of crashes.

Highway Safety Manual [28] also provides CMFs to evaluate potential crash effects of adding lanes by narrowing existing lanes and shoulders for urban freeways equipped with median barriers. These values are based on an earlier study by Bauer et al., 2004 [7]. However, these CMF are exclusively for conversion of only $12 \mathrm{ft}$ lanes into $11 \mathrm{ft}$ lanes and only for two types of conversion, that is, four to five lanes and five to six lanes. Recently, Bonneson et al. (2012) developed a generic prediction methodology for freeways using crash and road data from California, Maine, and Washington. This study developed a lane width CMF for fatal and injury crashes and presented most updated CMFs for any lane width and conversion. The proposed CMF equation can be applied for lane widths ranging from $10 \mathrm{ft}$ up to $13 \mathrm{ft}$; lane widths greater than or equal to $13 \mathrm{ft}$ have a constant CMF value of 0.963 [29].

\section{Motivation}

While literature has made a contribution towards operational impacts of reducing lane and shoulder width and increasing capacity by adding a lane, rarely any study attempts to understand the network or system level impacts. Moreover, identifying an optimal location for lane and shoulder width reduction before performing operations study is critical to the planning process.

Literature shows that an increase in network capacity (either by adding a lane or managing traffic flow) may lead to detrimental effects on the overall network [10]. From a more general perspective, this phenomenon underscores the importance of a careful and systematic analysis of investment in the corridors and networks. Not every addition in capacity can bring about all anticipated benefits and, in some cases, the situation may be worsened. In fact, traffic engineers have long known that restrictions of travel choices and the reduction in capacity may lead to better overall flow distribution patterns. This, for instance, is the underlying principle behind many traffic control schemes, such as ramp metering on freeway entrances.

Literature also shows that although reduced lane width and added lanes may provide localized benefits, this can subsequently lead to a decrease in network or safety performance because of the relocation of traffic operational bottlenecks $[6,22,23]$. According to the Highway Safety Manual (HSM), planning decisions may affect travel patterns over the network that subsequently leads to changes in the collective mobility and safety effects on the network [28]. Making improvements to a network without constraining the traffic flow pattern to be in accord with the user's behavior may lead to situations where congestion is increased by improving the capacity of a given link [10].

More interestingly, while capacity increase due to the lane addition leads to improved mobility, the narrow lanes have the potential to contribute towards an increase in predicted crashes. Choosing the corridor for lane width reduction without considering the system level impacts may lead to suboptimal solutions in terms of predicted crashes or overall network mobility [30]. The question posed in this paper is:

"How to decide corridors for narrowing lane and
shoulder widths to add an additional lane without
negatively influencing network performance mea-
sures and maximizing benefits?"

3.1. Motivational Example. Recently, there was discussion on exploring the feasibility of a similar option in some corridors of the Interstate Loop 410 in San Antonio, Texas, USA (Figure 1(a)). Figure 1(a) illustrates the San Antonio City network with major freeways (I-37, I-35, and I-10) and loops (Loop 


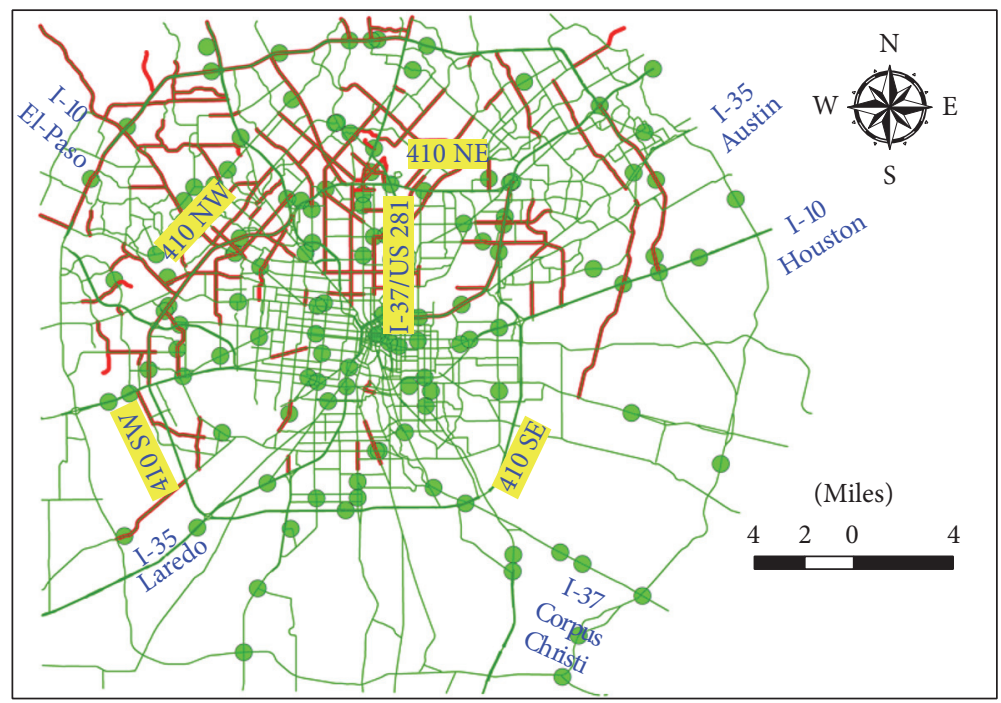

_ Roads_Eligible_for_Federal_Funding
- 2015 _Congested_Roadways
Fatal crashes

(a) San Antonio City network with congested roads and fatal crashes

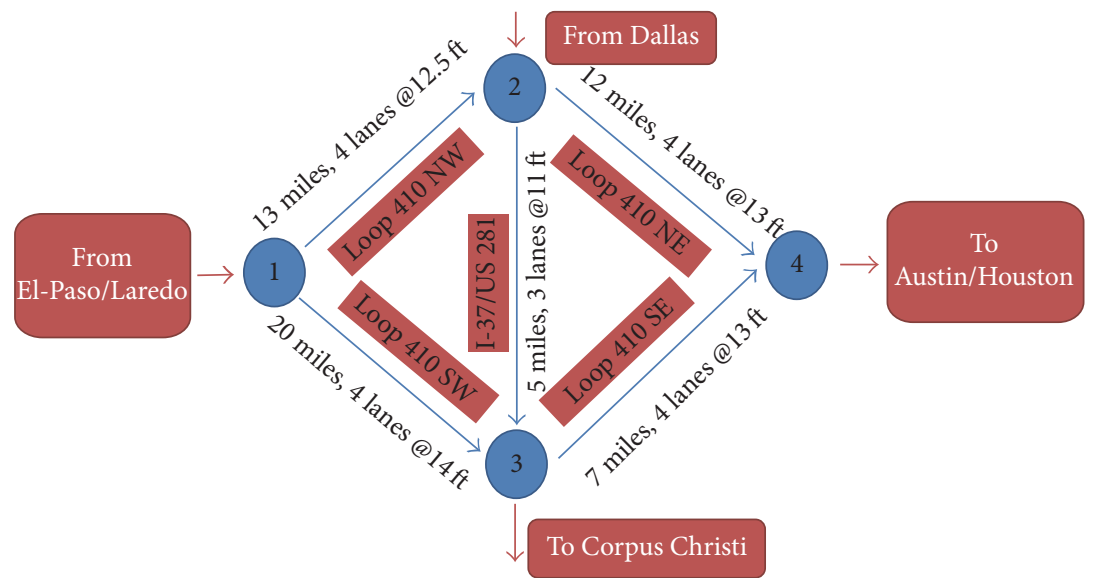

(b) Conceptual network

FIgURE 1: San Antonio City network and example network for conceptual explanation.

410) around the city. The figure also shows the city's congested corridors in red overlapping lines and fatalities on each road network are shown with the green points. Figure 1(b) is a simple representation of the network that consists of five roadlinks or corridors and four nodes (origin or destinations). This example network used for conceptual explanation of the problem is derived from the San Antonio City network. The nodes represent the origin or destination and links represent the corridors that are being considered for reducing lane and shoulder width for added capacity in terms of a new lane. For simplicity, we have considered only one-directional links and reported results are for this example network. It may be noted that a realistic network is solved later in this paper.

Table 1 shows the basic network parameters. The average free flow speed for the corridors is assumed as posted speeds; however, the effects of merging, diverging, and curvature on the speed are ignored in this example but will be considered in the real case study (in Case Study). The lane capacity is derived based on free flow speed as in HCM [12]. The origindestination demand is assumed 16,000 veh/hr from El-Paso \& Laredo to Austin/Houston and $8,000 \mathrm{veh} / \mathrm{hr}$ to Corpus Christi.

3.2. Discussion on Possible Solution. Table 2 illustrates the results of solving the example network at different corridor improvement levels by narrowing lane and shoulder widths. The first column presents three cases: the first case is the base-case, that is, no improvement in the network, the second case is narrowing all of the road-links/corridors and adding lanes without considering budget and network level impacts, and the third case is the most conservative (in terms of expenditure) and chooses the shortest congested corridor 
TABLE 1: Example network parameters.

\begin{tabular}{lcccc}
\hline Corridor/link & Free flow speed $(\mathrm{mph})$ & Capacity $(\mathrm{vph} / \mathrm{lane})$ & Fatal crashes & Nonfatal crashes \\
\hline Loop 410 NW & 65 & 2350 & 10 & 7 \\
Loop 410 SW & 70 & 2400 & 10 & 30 \\
I-37/US 281 & 60 & 2300 & 10 & 50 \\
Loop 410 NE & 65 & 2350 & 8 & 50 \\
Loop 410 SE & 70 & 2400 & 80 \\
\hline
\end{tabular}

TABLE 2: Result of analysis of example network.

\begin{tabular}{|c|c|c|c|c|c|c|}
\hline \multirow[b]{2}{*}{ Case (1) } & \multicolumn{4}{|c|}{ Link/corridor level performance measures (2) } & \multicolumn{2}{|c|}{ System level performance measures (3) } \\
\hline & Corridor & Corridor selection & Travel time (min) & Av. speed (mph) & Performance measure & $\begin{array}{c}\text { Value [\% change from } \\
\text { base-case] }\end{array}$ \\
\hline \multirow{5}{*}{$\begin{array}{l}\text { Base-case: no } \\
\text { improvements }\end{array}$} & $\begin{array}{l}\text { Loop } 410 \\
\text { NW }\end{array}$ & No & 18 & 44 & \multirow{2}{*}{$\begin{array}{c}\text { TSTT } \\
\text { (veh-min) }\end{array}$} & \multirow[t]{2}{*}{749,146} \\
\hline & $\begin{array}{l}\text { Loop } 410 \\
\text { SW }\end{array}$ & No & 23 & 51 & & \\
\hline & $\begin{array}{c}\text { I-37/US } \\
281\end{array}$ & No & 6 & 52 & \multirow[b]{2}{*}{$\operatorname{TSCC}(\$)$} & \multirow[t]{2}{*}{$\$ 80,019,000$} \\
\hline & $\begin{array}{l}\text { Loop } 410 \\
\text { NE }\end{array}$ & No & 14 & 52 & & \\
\hline & $\begin{array}{c}\text { Loop } 410 \\
\text { SE }\end{array}$ & No & 8 & 52 & Improvement cost & $\$ 0$ \\
\hline \multirow{5}{*}{$\begin{array}{l}\text { Improving all } \\
\text { the links }\end{array}$} & $\begin{array}{l}\text { Loop } 410 \\
\text { NW }\end{array}$ & Yes & 14 & $55[25 \%]$ & \multirow{2}{*}{$\begin{array}{c}\text { TSTT } \\
\text { (veh-min) }\end{array}$} & \multirow[t]{2}{*}{$625,476+[17 \%]$} \\
\hline & $\begin{array}{l}\text { Loop } 410 \\
\text { SW }\end{array}$ & Yes & 19 & $62[22 \%]$ & & \\
\hline & $\begin{array}{c}\text { I-37/US } \\
281\end{array}$ & Yes & 5 & 57 [10\%] & \multirow{2}{*}{ TSCC (\$) } & \multirow{2}{*}{$\begin{array}{l}\$ 81,856,150 \\
-[2.3 \%]\end{array}$} \\
\hline & $\begin{array}{l}\text { Loop } 410 \\
\text { NE }\end{array}$ & Yes & 12 & $59[13 \%]$ & & \\
\hline & $\begin{array}{c}\text { Loop } 410 \\
\text { SE }\end{array}$ & Yes & 7 & $61[17 \%]$ & Improvement cost & $\$ 100,575$ \\
\hline \multirow{5}{*}{$\begin{array}{l}\text { Suboptimal } \\
\text { improvements }\end{array}$} & $\begin{array}{l}\text { Loop } 410 \\
\text { NW }\end{array}$ & No & 18 & $44[0 \%]$ & \multirow{2}{*}{$\begin{array}{c}\text { TSTT } \\
\text { (veh-min) }\end{array}$} & \multirow[t]{2}{*}{$744,275+[0.6 \%]$} \\
\hline & $\begin{array}{l}\text { Loop } 410 \\
\text { SW }\end{array}$ & No & 23 & $52[2 \%]$ & & \\
\hline & $\begin{array}{c}\text { I-37/US } \\
281\end{array}$ & Yes & 5 & 57 [10\%] & \multirow{2}{*}{$\operatorname{TSCC}(\$)$} & \multirow[t]{2}{*}{$\begin{array}{l}\$ 81,428,031 \\
-[1.8 \%]\end{array}$} \\
\hline & $\begin{array}{l}\text { Loop } 410 \\
\mathrm{NE}\end{array}$ & No & 14 & $52[0 \%]$ & & \\
\hline & $\begin{array}{c}\text { Loop } 410 \\
\text { SE }\end{array}$ & No & 8 & $50[-4 \%]$ & Improvement cost & $\$ 6,000$ \\
\hline
\end{tabular}

+ sign next to the value means positive outcome relative to the base-case.

- sign means a negative outcome compared to the base-case.

for improvement and the last case is based on the model proposed in this paper.

The second column represents the road-link/corridor level performance measures. In the column (corridor selection), the Yes or No represents a selection of a corridor for improvement; if the value is Yes, the corridor is selected for adding a lane by narrowing the shoulder and lanes; otherwise it is not. The performance measures are the result of this implementation and shown in terms of travel time and average speed on the corridor. The value in square brackets shows the percentage improvement in the performance measures compared to the base-case. Although it is easy to comprehend changes in mobility (individual performance measure), the changes in crashes (fatal and nonfatal) may appear to be 
minor and unrealistic for this example. Hence, it has been shown in terms of total cost of crashes in the next column, as part of planner's objectives.

The third column shows the system level performance measures. The first measure total system travel time (TSTT) is the overall time spent by traffic in the network. The TSTT is computed as vehicles in the corridor during peak hour multiplied by travel time in the corridor, summed across all the corridors.

The second measure total system crash cost (TSCC) is the cost of fatal or nonfatal crashes multiplied by the predicted number of crashes after implementation of the project, summed across all the corridors. National Safety Council (NSC) estimates the average costs of fatal and nonfatal crashes as $\$ 1,420,000 /$ death and $\$ 78,700 /$ accident. We use these costs to normalize the objective function by providing weight to predicted fatal and nonfatal crashes and convert it into a single objective (TSCC). The individual crashes (fatal and nonfatal) cannot be simply added to form an objective function because the number of nonfatal crashes could be high compared to the fatal crashes. In addition, the higher weight (cost) to fatal crashes ensures that the algorithm treats them differently. The last performance measure among system performance measures (column 3 ) is the expenditure for narrowing the lanes and shoulder width.

The base-case shows the current travel conditions (i.e., speed, travel time) and system level performance of the network. In Table 2 (row 2), reducing lane and shoulder width of all the corridors and adding a lane improve the speed between 10 and 25 percent compared to the base-case (column 2). At the system level (column 3) the reduction in TSTT is 17 percent and shows the increase in system mobility. However, there is a slight increase in the system crash cost (TSCC) because of increase in predicted fatal and nonfatal crashes due to narrowing of the lanes. In reality, narrowing all lanes does not make sense and most state DOTs do not have budget to improve all major corridors.

The next case (suboptimal improvements) is a solution where planners try to minimize expenditure and impact by reducing the width and adding a lane only in the shortest congested corridor. This option does not improve the other corridor speeds except the selected corridor (10\% increase in the speed). Further, it deteriorates the safety of the network. The next section of the paper formulates this problem and presents the solution methodology that provides an optimal solution for the example network followed by realistic case studies.

\section{Proposed Model}

The nature of the presented problem in this paper involves two players: the first player is a planner who sets a road space management policy (i.e., narrowing lanes and adding a lane) and the second set of players is road users who respond to this policy in the form of traffic flow and speed on the road. This is a classic case of a problem that can be formulated as a bilevel programming (BLP) and expressed as follows: the planner wishes to determine an optimal policy as a function of control variables $y \in \mathfrak{R}^{n}$ (i.e., lane addition and narrow lanes) and the users response to these controls $x \in \mathfrak{R}^{m}$, generally in the form of a network flow or traffic, that is, $x=x_{i}$ for $i \in A$, where $A$ is the set of road-links or corridors in the network. This type of formulation prevents Braess Paradox [10] by anticipating the road user's reaction to the policy (lane addition and narrow lanes) and selecting the most optimal option.

In the proposed problem, the planner tries to minimize two competing objectives by adding capacity and narrowing the lane width. The first objective is to increase network mobility by minimizing total system travel time (TSTT). The second objective is total system crash cost, which is the product of the predicted number of crashes after lane modification, and cost of each type of crash. Crash costs normalize the objective function by providing weight to predicted fatal and nonfatal crashes. The higher cost of fatal crashes ensures that algorithm treats them differently. The smaller the number of predicted crashes in the network, the lower the value of total system crash cost. The formulation notations and the formulation follow:

Planner:

$$
\begin{aligned}
\min _{x \in R^{n}, y \in R^{m}} \mathrm{TSCC} & =\sum_{i \in I}\left(y_{i}\left[c^{f} \delta^{W_{l}} f_{i}+c^{n} \delta^{W_{l}} n_{i}\right]\right) \\
\min _{x \in R^{n}, y \in R^{m}} \mathrm{TSTT} & =\sum_{i \in I}\left(x_{i} t_{i}\left(x_{i}, y_{i}\right)\right)
\end{aligned}
$$

such that

$$
\begin{aligned}
\sum_{i \in I} g_{i}\left(b_{i}\right) \leq B \\
\delta^{W_{l}}= \begin{cases}e^{-0.0376\left(W_{l}-12\right)}, & W_{l}<13 \mathrm{ft} \\
0.963, & W_{l} \geq 13 \mathrm{ft}\end{cases} \\
y_{i}=\{0,1\}: \forall_{i \in I} .
\end{aligned}
$$

Road user:

$$
x_{i}=\underset{x_{i}}{\arg \min } \sum_{i \in I} \int_{0}^{x_{i}} t_{i}\left(x_{i}, y_{i}\right) d x
$$

$$
\begin{aligned}
\text { such that } q_{r s} & =\sum_{k \in k^{r s}} f_{k}^{r s} \forall(r, s) \in R S \\
x_{i} & =\sum_{(r, s) \in R S} \sum_{k \in K^{r s}} \delta_{a k}^{r s} f_{k}^{r s}, \quad \forall i \in I \\
f_{k}^{r s} & \geq 0, \quad \forall_{k} \in k^{r s}, \forall(r, s) \in R S, \\
q_{r s} & \geq 0, \quad \forall(r, s) \in R S .
\end{aligned}
$$

Equations (1)-(5) are the planner's perspective, that is, minimizing total crash cost (TSCC) and total system travel time (TSTT) simultaneously by determining a set of roadlinks/corridors to implement narrow lane and shoulder widths and adding a new lane. TSCC given by (1) is a product of the cost of each fatal or nonfatal crash $\left(c^{f}\right.$ or $\left.c^{n}\right)$ multiplied by crash modification factor $\left(\delta^{W_{l}}\right)$ for a lane width $W_{l}$ 
multiplied by the expected number of fatal or nonfatal crashes on that link $\left(f_{i}\right.$ or $\left.n_{i}\right)$. This is added across all road-links/corridors in the network that are selected for modification. Equation (2) shows the planner's objective to minimize TSTT is given by the sum of the product of traffic flow " $x_{i}$ " on the link " $i$ " and travel time $t_{i}(\cdot)$ as a function of traffic flow and added capacity on the link " $i$ "; (3) represents budget constraints; that is, total cost of restriping the lanes should be less than budget allocated, and (4) is the crash modification factor (CMF) as a function of lane width. For example, the CMF value for a $13 \mathrm{ft}$ lane is 0.963 which translates to a 4 percent crash reduction from the base condition of $12 \mathrm{ft}$ whereas a reduction from $12.5 \mathrm{ft}$ to $11.5 \mathrm{ft}$ lane leads to increase in CMF or crashes by 2 percent (CMF $=1.02) . y_{i}$ is a binary decision variable whose value is equal to one which represents implementation of narrow lanes on link " $i$ " and an increase in capacity of the link by one lane. This research uses the CMF equation, that is, a function of lane width, and implicitly considers traffic and geometric characteristics; however, this equation can be replaced by any CMF equation that is an exclusive function of traffic volume, lane width, and other road geometrics.

Equations (6) represent the road user's behavioral reaction towards the planner's policy decisions (narrowing the roads and added lanes) subject to the classical deterministic user equilibrium conditions. The deterministic user equilibrium is well known as static traffic assignment and is commonly used to model the road user behavior in transportation planning. This principle is based on the fact that individuals choose a route so as to minimize their travel time or travel cost, and such a behavior on the individual level creates equilibrium at the system (or network) level over a long period of time. More than 90 percent of the large MPOs and planners apply the user equilibrium assignment method to assign highway traffic or road network traffic [31].

\section{Solution Approach}

5.1. Solution Methodology. Figure 2 illustrates the generic solution methodology. The first level of the problem (i.e., (1)(5)) employs genetic algorithm since its efficacy in solving bilevel problems of a large real-sized network is proven in the literature, which is our final objective to make the proposed solution methodology realistic and applicable. The second level is solved by using a traditional Frank-Wolfe algorithm; the detailed algorithm is available in Sheffi, 1985 [32].

The algorithm starts by reading all inputs: network details, demand matrix, budget, travel time function, and investment function. The investment function is the defined cost of restriping the road-link/corridors per unit mile per lane. A population of link binary decision vectors (that decides if road-link is chosen for reducing lane width) is created and randomly initialized. These trial link vectors are then translated into the current road-link capacity vector. The lower level algorithm is then invoked with the current roadlink capacity vector where the origin-destination demand matrix is assigned to the network using the formulation given by (6). It is solved using Frank-Wolfe algorithm.
The output of the lower level is in the form of roadlink/corridor traffic flows and lane width that are further used to predict crashes on the corridor, the travel time, and average speeds. Next, the total system travel time is computed as the sum of the product of the link travel time and link flows in the network. Similarly, total system crash cost is computed by multiplying the predicted number of crashes by the cost of each type of crashes for the whole network. Thus, the total system travel time and the total system crash cost computed will form the two objective function values of the current generation. If the algorithm is satisfied with the solution (i.e., the minimum value of the objective function is obtained within budget), the process is terminated. Otherwise, a new set of binary decision variables is generated in the algorithm and all the above-mentioned steps are repeated.

The optimal solutions are reported in the form of total system travel time, total system crash cost, vector identifying road-links/corridors that are selected, travel times, average speeds, and total expenditure. Since we have two competing objectives we normally get multiple sets of solutions that satisfy either of the objectives but rarely both simultaneously, that is, no single solution that results in the least total system travel time and system crash cost.

5.2. Comparison of Results of Example Network. Table 3 shows the solution of the example network (described in the earlier section) using the system level transportation programming methodology developed and described in this paper. The solution obtained in this case is efficient in terms of corridor level performance measures, that is, increase in speeds by $8-10 \%$ and improved system level mobility (17\%). Compared to improving all the links (Table 2), this is the most cost-effective solution (expenditure $\$ 60,600$ ) that not only increases speed and mobility but will also result in lesser system crash cost and hence a number of crashes. Compared to suboptimal solution this solution not only improves the system travel time but also identifies corridors that will not contribute to increase in crashes.

In this small example, we showed how the optimal choice of a corridor not only provides a substantial increase in mobility in a cost-effective way but also increases the safety of a given transportation network.

\section{Case Studies and Results}

6.1. Data. The efficacy of the proposed solution methodology was tested on a small size city network and a large city network. The large network is the San Antonio city network. The data for the San Antonio city network was obtained and converted into a node-link network. The free flow speed, lane width, and capacity were obtained for eleven different road functional classes including urban and rural principal arterials. The San Antonio city network has 3063 road-links and around 3000 nodes (either junctions or origin/destinations). The free flow speed, lane width, and capacity were obtained for eleven different road functional classes including urban and rural principal arterials The peak hour origin-destination demand for the current year was not available before publication of this paper; hence 


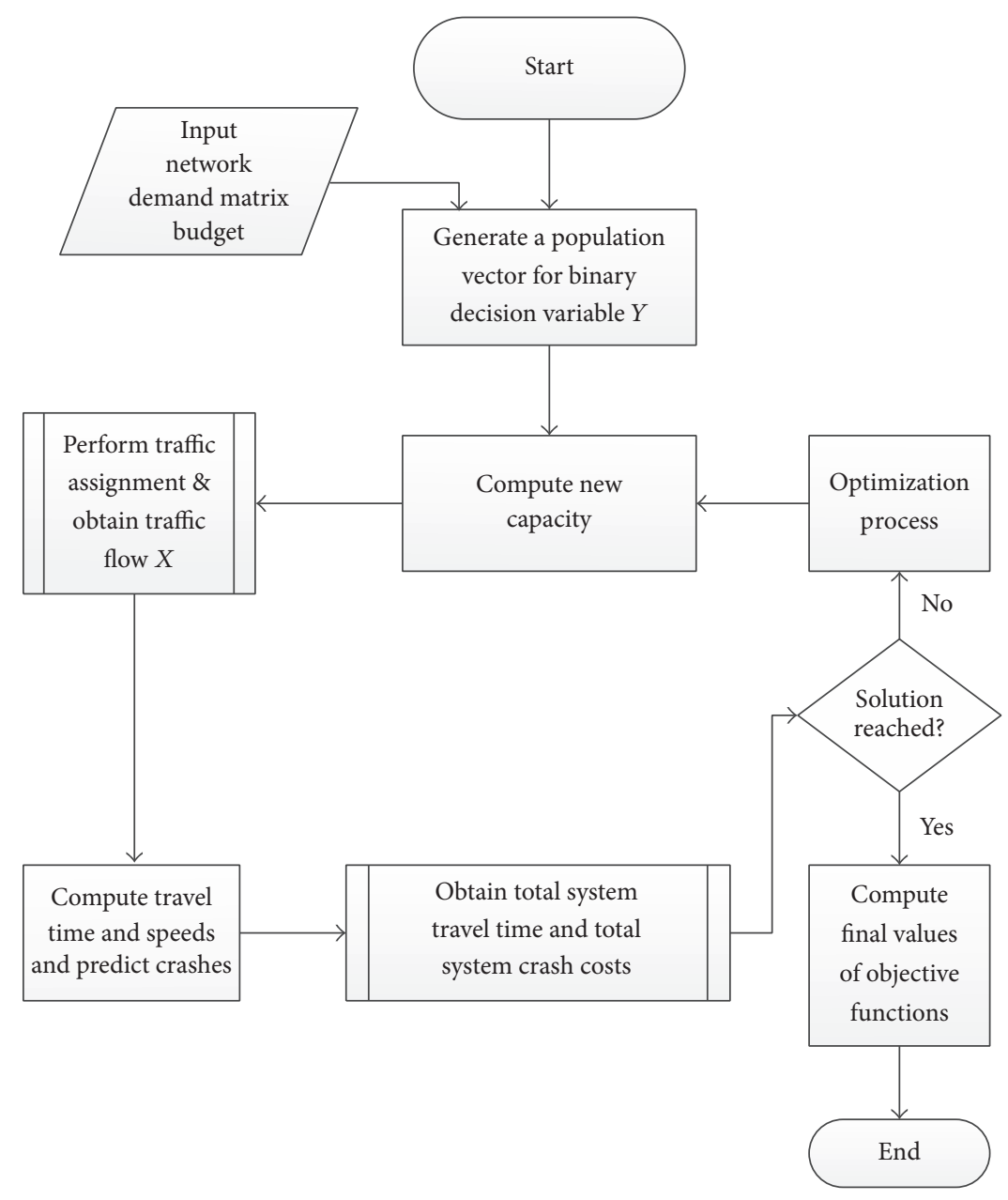

FIGURE 2: Flowchart illustrating solution methodology.

TABLE 3: Result of analysis of example network.

\begin{tabular}{|c|c|c|c|c|c|c|}
\hline \multirow{2}{*}{ Case (1) } & \multicolumn{4}{|c|}{ Link/corridor level performance measures (2) } & \multicolumn{2}{|c|}{ System level performance measures (3) } \\
\hline & Corridor & Corridor selection & Travel time (min) & Av. speed (mph) & Performance measure & $\begin{array}{c}\text { Value [\% change from } \\
\text { base-case] }\end{array}$ \\
\hline \multirow{5}{*}{$\begin{array}{l}\text { Optimal } \\
\text { improvements* }\end{array}$} & $\begin{array}{c}\text { Loop } 410 \\
\text { NW }\end{array}$ & No & 16 & $50[14 \%]$ & \multirow{2}{*}{$\begin{array}{c}\text { TSTT } \\
\text { (veh-min) }\end{array}$} & \multirow[t]{2}{*}{$669,742+[15 \%]$} \\
\hline & $\begin{array}{l}\text { Loop } 410 \\
\text { SW }\end{array}$ & Yes & 21 & $58[14 \%]$ & & \\
\hline & I-37/US 281 & No & 5 & $58[12 \%]$ & \multirow[b]{2}{*}{ TSCC $(\$)$} & \multirow{2}{*}{$\begin{array}{l}\$ 79,566,231 \\
\quad+[0.5 \%]\end{array}$} \\
\hline & $\begin{array}{l}\text { Loop } 410 \\
\text { NE }\end{array}$ & Yes & 13 & $57[10 \%]$ & & \\
\hline & $\begin{array}{l}\text { Loop } 410 \\
\quad \text { SE }\end{array}$ & No & 8 & $56[8 \%]$ & Improvement cost & $\$ 60,600$ \\
\hline
\end{tabular}

${ }^{*}$ Solution obtained by the proposed method in this paper.

the author used a synthetically generated demand matrix to present the case study. In this study, we consider only those locations where minimum lane width is $12.5 \mathrm{ft}$ and there is the possibility of reducing lane width and incorporating reduced shoulder width to provide an extra lane.
The small sized city network used in this study is comprised of 17 intersections and 56 bidirection road-links. Various traffic flows, network parameters, OD demand matrix, and link characteristics for this network are in Sharma et al., 2011 [33]. The annualized cost of restriping including 


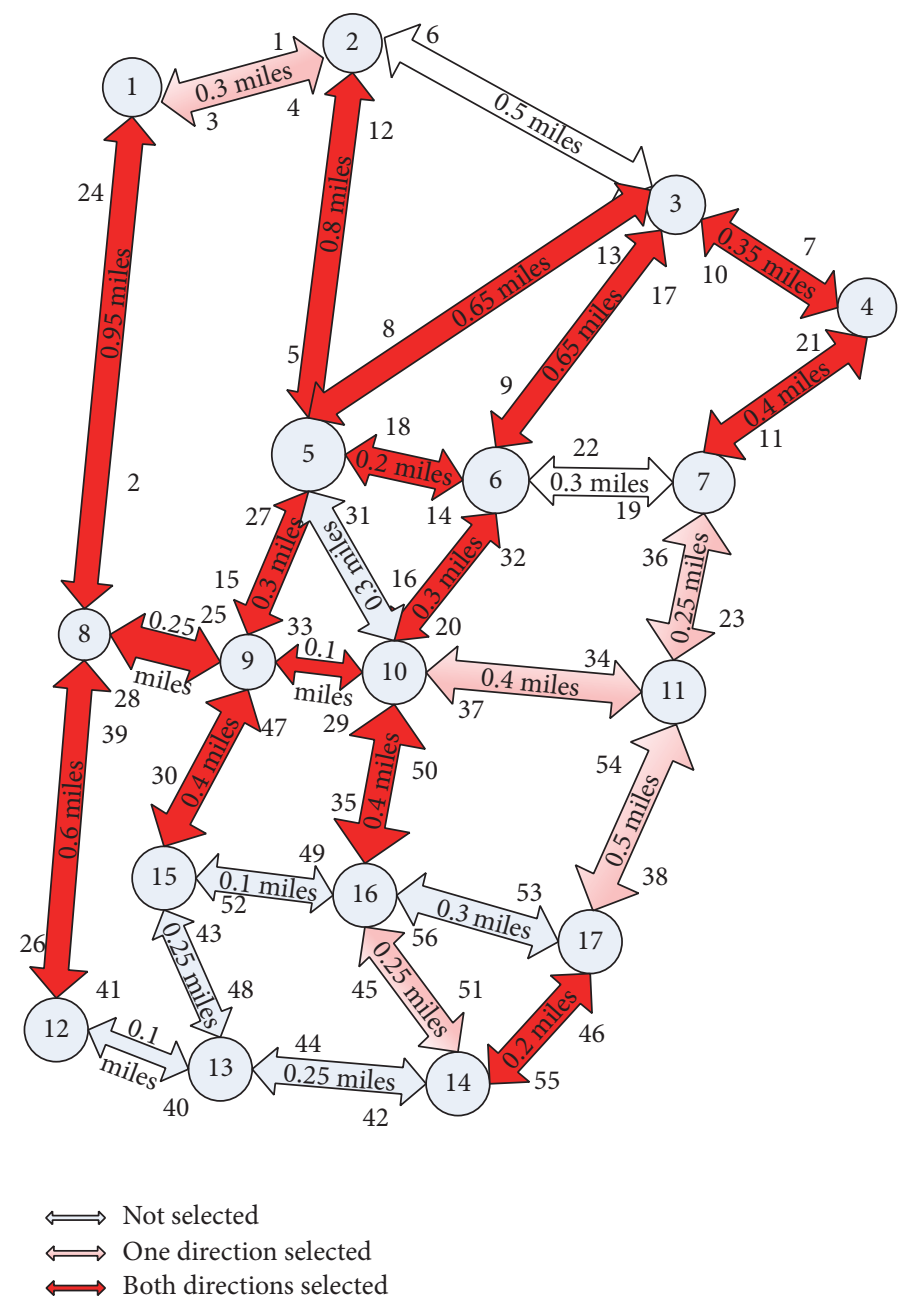

FIGURE 3: Small city network.

personnel, material, storage, and equipment cost obtained from Texas Department of Transportation (TxDOT) was around $\$ 665 / \mathrm{mile} / \mathrm{lane}$. For the case study paper assumes the cost of restriping $\$ 800 /$ mile/lane to incorporate all the miscellaneous costs. It may be noted that the developed methodology is not dependent on this cost assumption and any other cost can act as input into the model.

6.2. Case Study. In the case study of the small sized city network, we use a budget of $\$ 20,000$ to improve the network by reducing lane and shoulder width and converting them into narrow lanes. The road network is shown in Figure 3, with the road-links/corridor selected for improvement marked in red color. The lighter color suggests only one direction was chosen for lane width reduction and the addition of a lane.

The results of the model in terms of system level performance measures are in Table 4. Two cases are shown, the first case is no improvement case, that is, the base-case, and the second case shows solutions for minimum system travel time among many other solutions. The result is compared with the base-case; the numbers in the square bracket show percentage improvement in each objective function value and speed.
Compared to the base-case, the improvement in system travel time is 32 percent in the network, whereas at an average the corridor speeds improve by 19 percent with spending around $\$ 10,500$. However, there is an increase in the total system crash cost compared to the base-case. This shows that narrow lanes have increased the possibility of crashes by 2 percent.

Since the presented model has two objectives, that is, minimizing crash cost TSCC and minimizing system travel cost TSTT with the conflicting nature, there is no single solution (set of corridors for lane width reduction) that simultaneously results in minimum TSTT and TSCC. This means that there can be a solution with least value of TSTT but not TSCC and vice versa. In addition, in multiobjective problems, there is a spectrum of solutions that result in different values of each of these objectives as shown in Figure 4. Each of the points in Figure 4 represents a solution with a set of corridors/links chosen for improvement and resulting values of TSCC and TSTT objectives. This means that planner has not only one solution (as mentioned in second row of Table 4) but also many other solutions to choose from. For example, the planner has another solution (with different corridors for lane width reduction) that results 
TABLE 4: Solution for the small city network.

\begin{tabular}{|c|c|c|}
\hline \multirow{2}{*}{ Case } & \multicolumn{2}{|c|}{ System level performance measures } \\
\hline & Performance measure & Value \\
\hline \multirow{4}{*}{ Base-case: no improvements } & TSTT (veh-min) & 389,365 \\
\hline & Average link speed & $26 \mathrm{mph}$ \\
\hline & $\operatorname{TSCC}(\$)$ & $\$ 357,771,000$ \\
\hline & Improvement cost & $\$ 0$ \\
\hline \multirow{5}{*}{ Optimal solution (from multiple solutions) } & TSTT (veh-min) & $262,952+[32 \%]$ \\
\hline & Average link speed & $31 \mathrm{mph}+[19 \%]$ \\
\hline & $\operatorname{TSCC}(\$)$ & $\$ 365,726,685-[2 \%]$ \\
\hline & Improvement cost & $\$ 10,578$ \\
\hline & Budget & $\$ 20,000$ \\
\hline
\end{tabular}

+ sign next to the value means positive outcome relative to the base-case.

- sign means a negative outcome compared to the base-case.

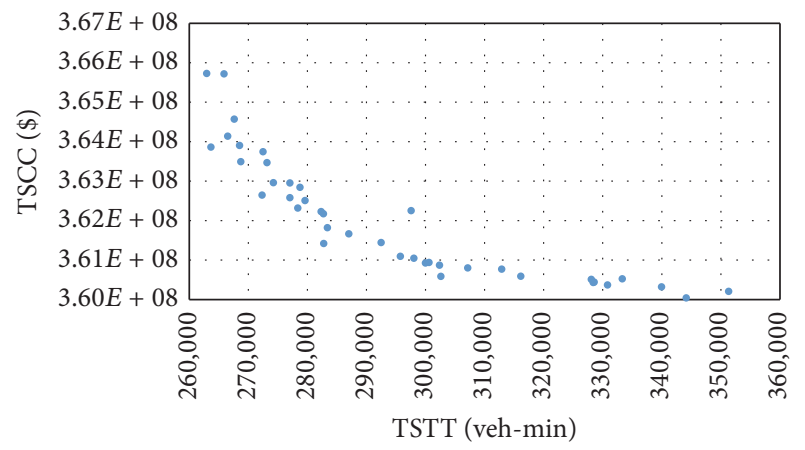

Figure 4: Multiple solutions from solving for two objectives (total system crash cost versus total system travel time).

in a 12 percent decrease in total system travel time and an 8 percent increase in average speed while there is no increase in predicted crashes or total system crash cost. The expenditure to implement that strategy is around $\$ 14,000$.

Figure 5 shows the San Antonio City network with nodes (as junctions) and road-links/corridors. This image illustrates selected corridors using ArcGIS for adding another lane while reducing lane and shoulder width in red color in Figure 5. However, these were not the only road segments that are an optimal candidate for lane and shoulder width reduction, rather they were a corridor of interest. If some smaller sections are selected planner can ignore or combine them for operational analysis. Also, the planner can ignore those road segments where the geometric configurations at ramps may not align with implementing new lane widths system-wide. These results are based on the synthetic OD demand matrix due to unavailable OD matrix for the year 2015. Nevertheless, the resulting selection of the corridors demonstrates the efficacy and applicability of the proposed model at a large network level.

\section{Conclusion}

While literature contributed towards operational impacts of reducing lane and shoulder width to add a new lane, there rarely seems to be a study that attempts to understand the network or system level impacts. Past studies indicate a likelihood that reduced lane width may provide localized benefits, at the expense of system level performance measures (average travel time and crashes) because of the relocation of traffic bottlenecks. Moreover, identifying an optimal location for lane and shoulder width reduction before performing traffic operations study is critical to the planning process. As the pattern of trips on the network changes, the collective mobility and safety effects on the network may change.

This research acts as a stepping-stone in leveraging transportation programming in identifying the optimal location for reduction of lanes and shoulder width without negatively influencing the network performance measures. The proposed methodology has the following contribution towards investment decision-making in road space management strategies. First, the model provides planners system level improvement options to increase mobility significantly while minimizing crashes within a limited budget. Second, the model provides planners multiple solutions in terms of a set of road-links/corridors that need improvement and system level improvements upon implementation of each strategy. Third, the proposed methodology is scalable and generic and can be modified and employed for any transportation network and any number of improvement options. The methodology is also independent of any CMF and cost assumptions.

It should be noted that this study is not a replacement for operational level analysis but serves as a first step in identifying optimal locations for lanes and shoulder width reduction before performing the operational level analysis. The proposed model being a mathematical model suffers from some limitations, as it does not map the reality as it is, and is based on assumptions such as the following: (a) users choose roads with minimum travel time and have perfect knowledge of travel time; (b) capacity is affected linearly with reduced lane width and speeds; (c) crashes predicted using crash modification factors are within acceptable probability; (d) different impacts of different type of crashes are ignored (including heavy vehicles). Another limitation is that the study ignores that the geometric configurations at ramps may not align with implementing new lane widths system-wide. 


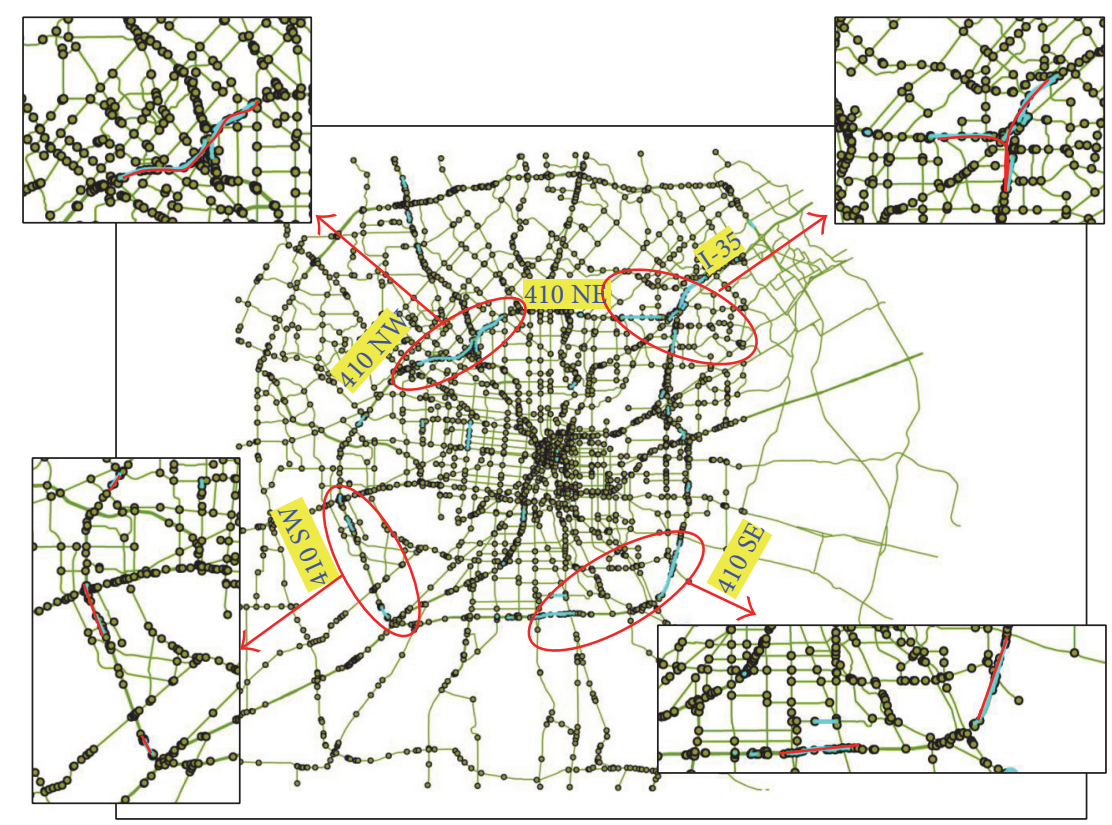

FIGURE 5: Corridors selected by proposed method for reducing lane and shoulder width (marked in red in zoomed-in parts) in San Antonio city network.

In the future, the developed framework will be refined to consider more sophisticated crash prediction methods, integration with simulation models, add lane-use purpose (general or HOV), investigate safety implications at off-peak, and perform a case study with new updated data.

\section{Notations}

B: $\quad$ Allocated budget for restriping and narrowing lanes and shoulder $(\$)$

$b_{i}$ : $\quad$ Expenditure for restriping the lanes in road $i$

$c^{f}: \quad$ Cost of single fatal crash $(f)$

$c^{n}: \quad$ Cost of single nonfatal crash $(n)$

$\delta^{W_{l}}: \quad$ Crash modification factor for lane width $W_{l}$

$f_{i}: \quad$ Number of fatal crashes on road $i$

$n_{i}: \quad$ Number of nonfatal crashes on road $i$

$y_{i}: \quad$ A binary decision variable equal to 1 if lane and shoulder width are reduced and a lane is added

$x_{i}: \quad \quad \quad \quad$ Traffic flow on road $i$

$t_{i}\left(x_{i}, y_{i}\right)$ : Travel time as a function of traffic flow $x_{i}$ on road network and capacity change $y_{i}$

$f_{k}^{r s}: \quad$ Traffic flow on path $k$ between OD pair $r-s$

$\delta_{i, k}^{r s}: \quad 1$ if route $k$ between OD pair $r$-s uses road $i$ and 0 otherwise.

\section{Competing Interests}

The author declares that there is no conflict of interests regarding the publication of this paper.

\section{References}

[1] Texas A\&M Transportation Institute (TTI), Urban Mobility Report, 2015, http://mobility.tamu.edu/ums/report/.

[2] American Society of Civil Engineers (ASCE), Report Card for America's Infrastructure, 2013, http://www.infrastructurereportcard.org.

[3] American Association of State Highway and Transportation Officials (AASHTO), State Transportation Funding, 2013, http://www.transportation-finance.org/pdf/featured_documents/ state\%20transportation\%20funding\%20proposals\%202013-0415.pdf.

[4] Texas Department of Transportation (TxDOT), Understanding State Road and Highway Funding in Texas, 2015, https://ftp .dot.state.tx.us/pub/txdot-info/fin/funding_sources.pdf.

[5] K. C. Sinha, S. Labi, S. Hodge, G. Tine, and H. Shah, "An assessment of highway financing needs in Indiana," Tech. Rep. FHWA/IN/JTRP/2005-09, Joint Transportation Research Program, Indiana Department of Transportation and Purdue University, West Lafayette, Ind, USA, 2005.

[6] National Research Council, NCHRP Report 613: Guidelines for Selection of Speed Reduction Treatments at High-Speed Intersections, The National Academies Press, Washington, DC, USA, 2008.

[7] K. M. Bauer, D. W. Harwood, W. E. Hughes, and K. R. Richard, "Safety effects of narrow lanes and shoulder-use lanes to increase capacity of urban freeways," Transportation Research Record: Journal of Transportation Research Board, vol. 1897, pp. 71-80, 2004.

[8] C. V. Zegeer, C. Seiderman, P. Lagerwey, M. Cynecki, M. Ronkin, and B. Schneider, "Pedestrian facilities users guide: providing safety and mobility," Tech. Rep. FHWA-RD-01-102, U.S. Department of Transportation, 2002.

[9] Federal Highway Administration (FHWA), "Safety evaluation of lane and shoulder width combinations on rural, two-lane, 
undivided roads," Technical Summary FHWA-HRT-09-031, 2009, http://www.fhwa.dot.gov/publications/research/safety/ 09032/.

[10] D. Braess, A. Nagurney, and T. Wakolbinger, "On a paradox of traffic planning," Transportation Science, vol. 39, no. 4, pp. 446450, 2005.

[11] American Association of State Highway and Transportation Officials (AASHTO), A Policy on Geometric Design of Highways and Streets, AASHTO, Washington, DC, USA, 6th edition, 2010.

[12] Transportation Research Board (TRB), Highway Capacity Manual, Transportation Research Board (TRB), Washington, DC, USA, 2010.

[13] F. Rooney, Restriping Freeways for Added Lanes, California Division of Highways, 1972.

[14] A. C. Estep and K. Moskowitz, Getting the Most out of a Freeway System, vol. 153 of Transportation Research Board Special Report, 1975, http://trid.trb.org/view.aspx?id=40354.

[15] W. McCasland, "Use of freeway shoulders to increase capacity," Tech. Rep. FHWATX78-210-2, Texas Department of Transportation (TxDOT), Austin, Tex, USA, 1978.

[16] C. L. Dudek and S. H. Richards, "Evaluation of traffic control plans at reconstruction sites FHWA/TX," Tech. Rep. 86/26+3213F, 1986.

[17] S. H. Richards, R. C. Wunderlich, and C. L. Dudek, "Field evaluation of work zone speed control techniques," Transportation Research Record: Journal of Transportation Research Board, vol. 1035, pp. 66-78, 1985.

[18] N. M. Rouphail, Z. S. Yang, and J. A. Fazio, "Comparative study of short- and long-term urban freeway work zones," Transportation Research Record, vol. 1163, pp. 4-14, 1988.

[19] R. F. Benekohal, L. M. Kastel, and M. I. Suhale, "Evaluation and summary of studies in speed control methods in work zones," Tech. Rep., FHWA, U.S. Department of Transportation, 1992.

[20] M. Choueiri Elias, R. Lamm, J. H. Kloeckner, and T. Mailaender, "Safety aspects of individual design elements and their interactions on two-lane highways: international perspective," Transportation Research Record: Journal of Transportation Research Board, vol. 1445, pp. 34-46, 1994.

[21] J. L. Gattis, "Urban street cross-section and speed issues," in Proceedings of the Urban Street Symposium, Transportation Research E-Circular E-C019, Transportation Research Board, National Research Council, Dallas, Tex, USA, June 1999.

[22] K. M. Bauer, D. W. Harwood, W. E. Hughes, and K. R. Richard, "Safety effects of narrow lanes and shoulder-use lanes to increase capacity of Urban freeways," Transportation Research Record: Journal of Transportation Research Board, no. 1897, pp. 71-80, 2004.

[23] S. A. Cooner and S. E. Ranft, "Safety evaluation of bufferseparated high-occupancy vehicle lanes in Texas," Transportation Research Record: Journal of Transportation Research Board, no. 1959, pp. 168-177, 2006.

[24] T. Ben-Bassat and D. Shinar, "Effect of shoulder width, guardrail and roadway geometry on driver perception and behavior," Accident Analysis and Prevention, vol. 43, no. 6, pp. 2142-2152, 2011.

[25] J. Bonneson, D. Lord, K. Zimmerman, K. Fitzpatrick, and M. Pratt, "Development of tools for evaluating the safety implications of highway design decisions," Report 0-4703-4, TxDOT, Austin, Tex, USA, 2007.

[26] A. Bonneson James and M. Pratt, "Roadway safety design workbook," Tech. Rep. FHWA/TX-09/0-4703-P2, Texas Transportation Institute, Texas A \& M University System, 2009.
[27] F. Gross and P. P. Jovanis, "Estimation of the safety effectiveness of lane and shoulder width: case-control approach," Journal of Transportation Engineering, vol. 133, no. 6, pp. 362-369, 2007.

[28] AASHTO, Highway Safety Manual, American Association of State Highway and Transportation Officials (AASHTO), Washington, DC, USA, 2010.

[29] J. A. Bonneson, S. Geedipally, M. P. Pratt, and D. Lord, NCHRP Project 17-45: Safety Prediction Methodology and Analysis Tool for Freeways and Interchanges, 2012, http://onlinepubs.trb.org/ onlinepubs/nchrp/docs/NCHRP17-45_FR.pdf.

[30] S. Sharma and T. V. Mathew, "Multiobjective network design for emission and travel-time trade-off for a sustainable large urban transportation network," Environment and Planning B: Planning and Design, vol. 38, no. 3, pp. 520-538, 2011.

[31] Vanasse Hangen Brustlin, "Determination of the state of the practice in metropolitan area traffic forecasting: Findings of the surveys of metropolitan planning organizations," Transportation Research Board, June 2015, http://onlinepubs.trb.org/ onlinepubs/reports/vhb-2007-final.pdf.

[32] Y. Sheffi, Urban Transportation Networks: Equilibrium Analysis With Mathematical Programming Methods, John Wiley \& Sons, New York, NY, USA, 1985.

[33] S. Sharma, T. V. Mathew, and S. V. Ukkusuri, "Approximation techniques for transportation network design problem under demand uncertainty," Journal of Computing in Civil Engineering, vol. 25 , no. 4 , pp. $316-329,2011$. 


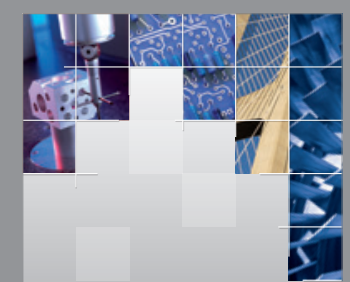

\section{Enfincering}
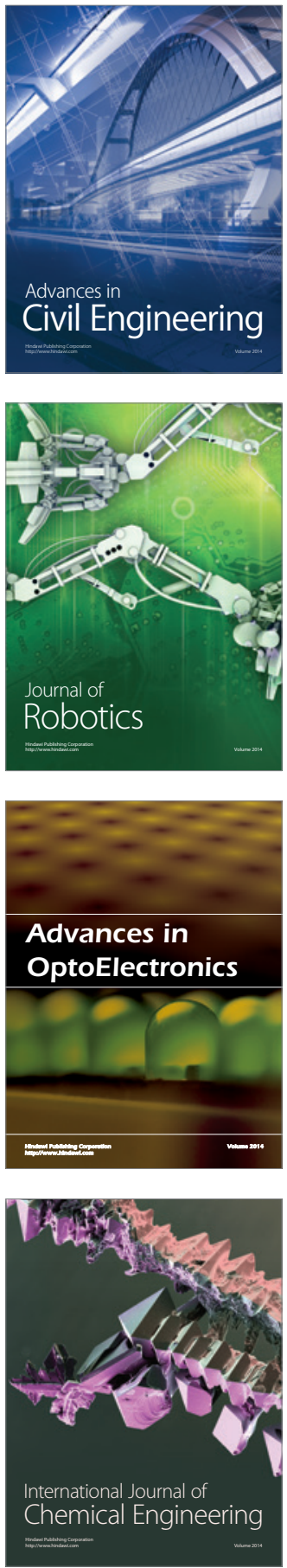

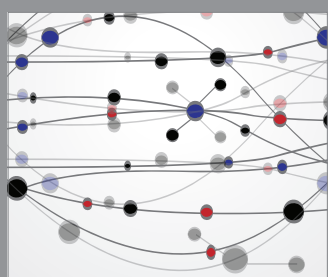

The Scientific World Journal

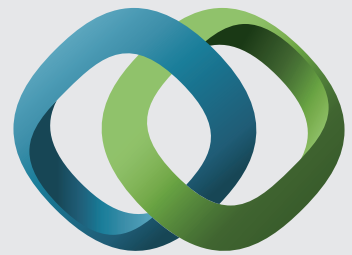

\section{Hindawi}

Submit your manuscripts at

https://www.hindawi.com
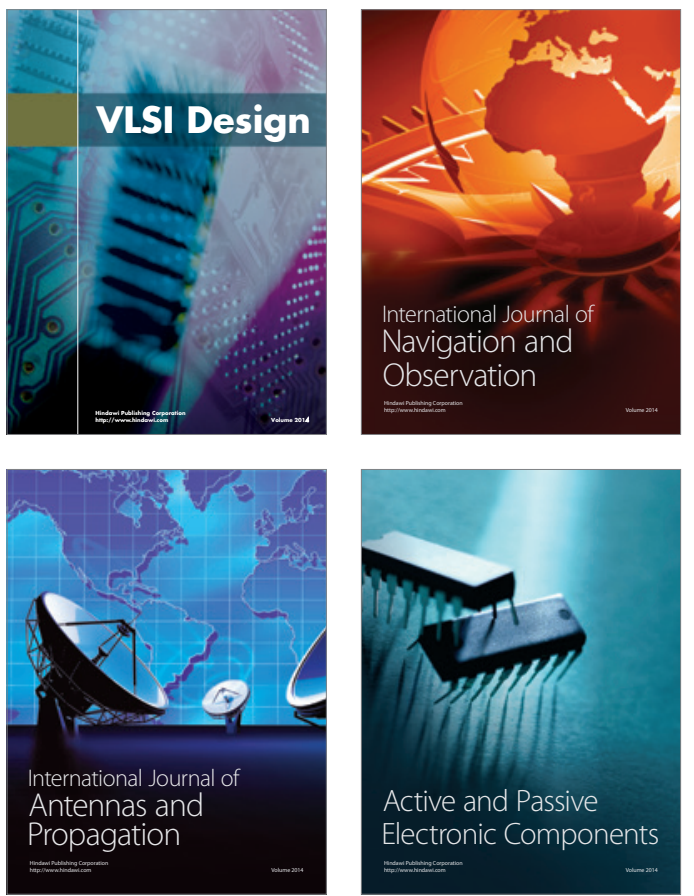
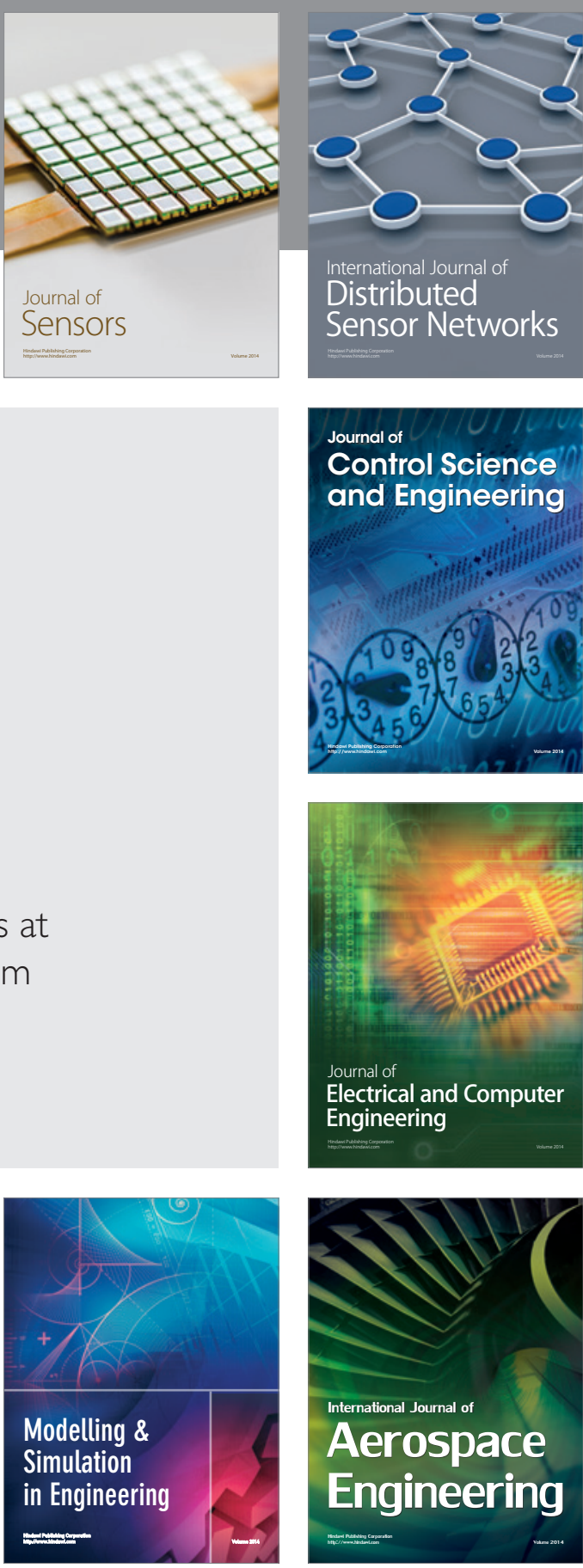

International Journal of

Distributed

Sensor Networks

$-$

Joumal of

Control Science

and Engineering
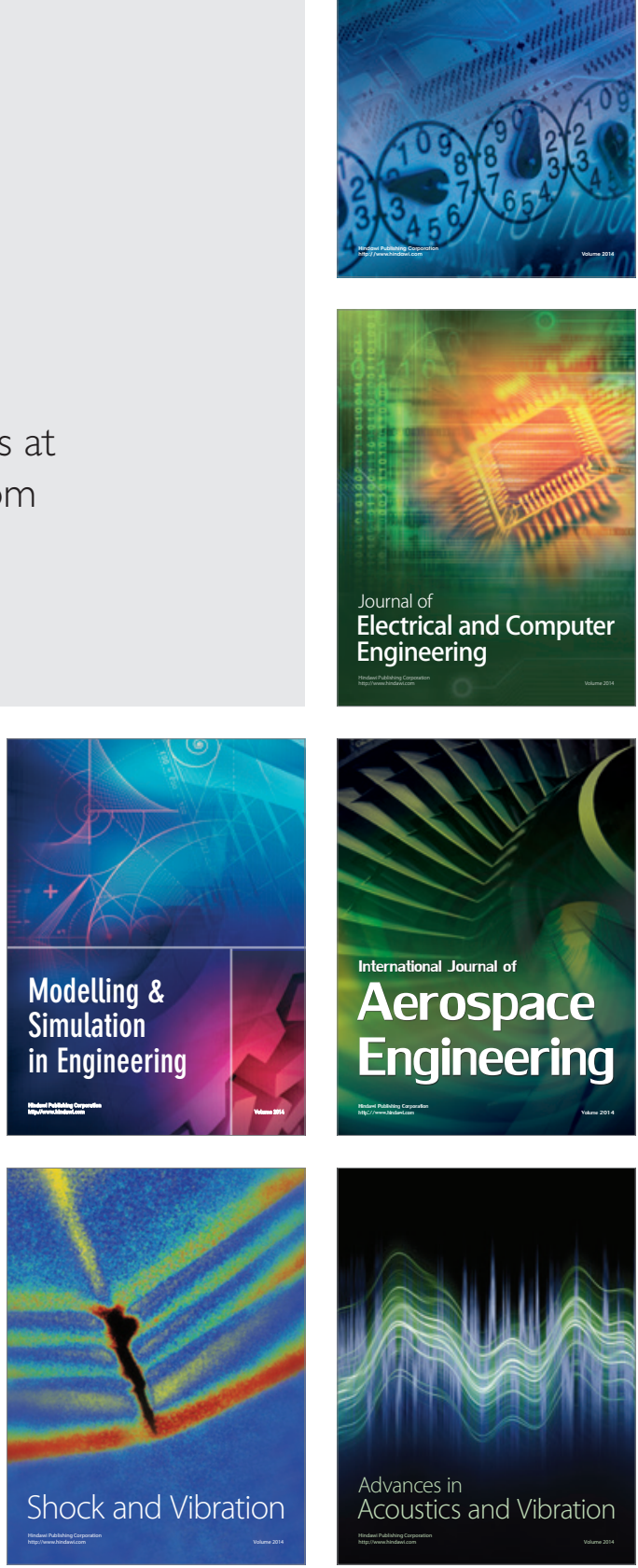